\title{
Improved quality of life after lung volume reduction surgery
}

\author{
J. Hamacher*, S. Büchi", C.L. Georgescu*, U. Stammberger*, R. Thurnheer*, K.E. Bloch*, \\ W. Weder", E.W. Russi*
}

Improved quality of life after lung volume reduction surgery. J. Hamacher, S. Büchi, C.L. Georgescu, U. Stammberger, R. Thurnheer, K.E. Bloch, W. Weder, E.W. Russi. (C) ERS Journals Ltd 2002.

ABSTRACT: Lung volume reduction surgery (LVRS) improves dyspnoea, pulmonary function, and physical performance in patients with severe pulmonary emphysema. This study investigated the impact of LVRS on health-related quality of life (HRQL) over a 2-yr period following surgery.

Thirty-nine consecutive patients were prospectively assessed before LVRS, and followed over 24 months postoperatively. The assessments included pulmonary function, dyspnoea (Medical Research Council (MRC) dyspnoea score), 6-min walking distance (6MWD) and HRQL using the Short Form 36-item questionnaire (SF-36) .

Several domains of SF-36 improved considerably over 2 yrs after surgery: Physical Functioning: $39 \pm 4$ (mean \pm SEM) versus $16 \pm 2$ ( $<<0.01$ ); Vitality: $51 \pm 3$ versus $32 \pm 3$ $(p<0.01)$; Social Functioning: $72 \pm 4$ versus $51 \pm 5(p<0.01)$. Also, improvements in pulmonary function (forced expiratory volume in one second (FEV1): $27 \pm 1 \%$ predicted, residual volume (RV)/total lung capacity (TLC): $0.65 \pm 0.01), 6 \mathrm{MWD}(274 \pm 16 \mathrm{~m})$ and dyspnoea (MRC: $3.9 \pm 01$ ) were sustained for up to 2 yrs after LVRS (FEV1 36 $\pm 2 \%$ pred, RV/TLC: $0.58 \pm 0.02$; 6 MWD: $342 \pm 19 \mathrm{~m}$; MRC: $2.0 \pm 0.2 ; \mathrm{p}<0.05)$.

In patients with severe emphysema, lung volume reduction surgery had positive effects on health-related quality of life and pulmonary function over 2 yrs.

Eur Respir J 2002; 19: 54-60.
*Pulmonary Division, Dept of Internal Medicine, " Division of Thoracic Surgery, Dept of Surgery, "Division of Psychosocial Medicine, Dept of Psychiatry, University Hospital, Zürich, Switzerland.

Correspondence: E.W. Russi, Pulmonary Division, Dept of Internal Medicine, University Hospital, CH- 8091 Zürich, Switzerland.

Fax: 4112554451

Keywords: Emphysema, lung volume reduction surgery, quality of life

Received: August 242001 Accepted after revision September 2 2001

This study was supported by grant no. 3200-043358; 95.1 from the Swiss National Science Fund and by a grant from the Zürich Lung League.
Chronic obstructive pulmonary disease (COPD) is a fast growing cause of morbidity and mortality in the industrialized nations. In severe forms COPD is accompanied by emphysema and has the potential to substantially impair health-related quality of life (HRQL) in an affected individual [1].

Comprehensive pulmonary rehabilitation in symptomatic patients with COPD does not alter their pulmonary function, but improves exercise tolerance and decreases dyspnoea at a given work load [2]. A beneficial effect of rehabilitation on quality of life was demonstrated in several investigations [3-8].

Many groups have shown that lung volume reduction surgery (LVRS) improves dyspnoea, lung function and exercise tolerance in selected patients with advanced pulmonary emphysema [9-11], but only a few studies have reported the effects of LVRS on quality of life $[12,13]$. Two groups used the combination of preoperative rehabilitation and consecutive LVRS and assessed the patients with the same instruments, i.e. the Short Form 36-item questionnaire (SF-36), as in the present study [10, 14]. Others followed aspects of quality of life in LVRS for up to 6 months only [11, 15-18] or 12 months [19] or reported for a longer time period, but only a small number of patients were followed for up to 18 months $[12,13]$.

The purpose of this study was to prospectively investigate the impact of LVRS on HRQL for up to 2 yrs and to correlate changes in HRQL parameters with dyspnoea, timed walking distance and lung function.

\section{Methods}

Thirty-nine consecutive patients ( 17 females), with a mean \pm SD age of $61 \pm 1 \mathrm{yrs}$, were studied. All were previous heavy smokers and complained about severe dyspnoea (Medical Research Council (MRC) dyspnoea score: $3.9 \pm 0.1)$. They had severe obstruction to airflow, considerable pulmonary hyperinflation and a limited 6-min walking distance (6MWD) as shown in table 1. Patients were included from April 1996-November 1998. Capability to understand the questionnaires in the German language and a followup period of at least 2 yrs were required. The study population for quality of life assessment was smaller than the cohort of 83 patients who underwent bilateral LVRS by video-assisted thoracoscopy (VAT) at the Pulmonary Division, the Dept of Internal Medicine, University Hospital, Zürich from April 1996November 2000 for the following reasons: seven patients died, nine patients were lost for followup, five patients underwent lung transplantation, and the remainder of the patients had insufficient 
Table 1. - Health related quality of life, dyspnoea and lung function before and up to 2 yrs after lung volume reduction surgery

\begin{tabular}{|c|c|c|c|c|c|c|}
\hline & Preop. & 3 Months & 6 Months & 12 Months & 18 Months & 24 Months \\
\hline \multicolumn{7}{|l|}{ SF-36 } \\
\hline Physical Functioning & $16 \pm 2$ & $55 \pm 4 * * *$ & $51 \pm 4 * * *$ & $47 \pm 4 * * *$ & $43 \pm 4 * * *$ & $39 \pm 4 * * *$ \\
\hline Role Physical & $15 \pm 5$ & $46 \pm 7 * *$ & $53 \pm 7 * * *$ & $39 \pm 7 * *$ & $38 \pm 7 * *$ & $31 \pm 6^{*}$ \\
\hline Bodily Pain & $80 \pm 4$ & $80 \pm 4$ & $80 \pm 4$ & $74 \pm 5$ & $77 \pm 5$ & $79 \pm 5$ \\
\hline General Health & $45 \pm 3$ & $63 \pm 3 * * *$ & $61 \pm 4 * * *$ & $56 \pm 4 *$ & $53 \pm 3^{*}$ & $48 \pm 3$ \\
\hline Vitality & $32 \pm 3$ & $60 \pm 3 * * *$ & $60 \pm 3 * * *$ & $55 \pm 3 * * *$ & $50 \pm 3 * * *$ & $51 \pm 3 * * *$ \\
\hline Social Functioning & $51 \pm 5$ & $82 \pm 3 * * *$ & $85 \pm 3 * * *$ & $81 \pm 4 * * *$ & $80 \pm 4 * * *$ & $72 \pm 4 * * *$ \\
\hline Role Emotional & $60 \pm 7$ & $75 \pm 7$ & $79 \pm 6$ & $75 \pm 6$ & $73 \pm 7$ & $67 \pm 8$ \\
\hline Mental Health & $66 \pm 4$ & $79 \pm 3 * * *$ & $79 \pm 3 * *$ & $78 \pm 3 * *$ & $74 \pm 3 *$ & $75 \pm 2 * *$ \\
\hline Dyspnoea (MRC) & $3.9 \pm 0.1$ & $1.5 \pm 0.1 * * *$ & $1.5 \pm 0.1 * * *$ & $1.7 \pm 0.2 * * *$ & $1.8 \pm 0.2 * * *$ & $2.0 \pm 0.2 * * *$ \\
\hline FEV $1 \%$ pred. & $27 \pm 1$ & $45 \pm 2 * * *$ & $43 \pm 2 * * *$ & $40 \pm 2 * * *$ & $38 \pm 2 * * *$ & $36 \pm 2 * * *$ \\
\hline RV/TLC & $0.65 \pm 0.01$ & $0.49 \pm 0.02 * * *$ & $0.51 \pm 0.02 * * *$ & $0.53 \pm 0.02 * * *$ & $0.55 \pm 0.02 * * *$ & $0.58 \pm 0.02 * * *$ \\
\hline 6 min Walking Distance $\mathrm{m}$ & $274 \pm 16$ & $369 \pm 15^{* * *}$ & $372 \pm 16^{* * *}$ & $371 \pm 15^{* * *}$ & $353 \pm 18^{* *}$ & $342 \pm 19 * *$ \\
\hline
\end{tabular}

Data are presented as mean \pm SEM; SF-36: Short Form 36-item questionnaire; dyspnoea (MRC): Medical Research Council dyspnoea score; FEV1: forced expiratory volume in 1 second; RV: residual volume; TLC: total lung capacity; SF-36: best: 100 ; worst: 0 . *: $\mathrm{p} \leqslant 0.05 ; * *: \mathrm{p} \leqslant 0.01 ; * * *: \mathrm{p} \leqslant 0.0001$ versus preoperative value.

comprehension of the German language $(n=1)$ or a follow-up period of $<2$ yrs. Only two perioperative deaths (within 30 days of LVRS) were observed. The other patients died in the later course due to typical complications of COPD, i.e. pulmonary infection, respiratory failure, pulmonary emboli. The baseline data amongst the 39 patients with a follow-up for 2 yrs and the 33 patients with a briefer follow-up were comparable with respect to age, sex distribution, dyspnoea score, HRQL and pulmonary function except for a residual volume (RV)/total lung capacity (TLC) of $0.65(0.01)$ in those with a 2-yr follow-up as compared to the rest with a RV/TLC of $0.68(0.01)$ $(\mathrm{p}=0.03)$. The two groups also experienced comparable improvements in the various parameters at 3 months after surgery except for 6MWD, where the 2 -yr study group improved by $100 \mathrm{~m}$ from a baseline of $273 \mathrm{~m}$ and the other group by $48 \mathrm{~m}$ from a baseline of $284 \mathrm{~m}(\mathrm{p}=0.02)$.

All patients were selected for LVRS according to previously published criteria $[20,21]$ and gave written informed consent to a prospective study on outcome after LVRS which was approved by the hospital's ethic committee. No systematic pulmonary rehabilitation was performed pre- or postoperatively.

Patients were assessed for dyspnoea, pulmonary function, 6MWD, HRQL, chest radiographs, pulmonary computed tomography and lung perfusion scintigrams. At 3 and 6 months postoperatively and at 6-monthly intervals thereafter grading of dyspnoea, pulmonary function tests, 6MWD and HRQL were repeated.

Dyspnoea was rated according to the American Thoracic Society modified MRC dyspnoea score [22]. The patient describes the degree of dyspnoea which is graded with an integer from $0-4$. Zero means breathlessness only with strenuous exercise, 4 means that the patient is unable to leave the house or is breathless while dressing.

Pulmonary function tests were performed after inhalation of two puffs of salbutamol adhering to standard criteria [23, 24] with the Sensor Medics
Autobox plethysmograph (Yorba Linda, CA, USA). Reference values were in accordance to the European Community for Steel and Coal [24, 25].

For assessment of the 6MWD, the patients walked attended but without oxygen supplementation along the same hospital hallway.

For the assessment of HRQL, the German version of the Medical Outcomes Study SF-36, which contains eight domains (Physical Functioning, Role Physical, Vitality, General Health, Social Functioning, Role Emotional, Mental Health, Bodily Pain), was used [26]. The domain scores are rated so that higher values indicate better health (range 0-100) (see Appendix). The number of missing data was low $(<5 \%$ at any individual time point) and randomly distributed with respect to various domains of HRQL.

Surgical lung volume reduction was performed bilaterally by VAT as previously described [27].

\section{Data analysis}

Data are presented as mean \pm SEM. Unpaired t-tests for independent samples or repeated measurement analysis of variance (ANOVA) was performed, using contrast vector analysis to compare differences between specific postoperative and preoperative time points. Differences between proportions were analysed by Chi-squared tests. Univariate linear regression analysis of changes in pulmonary function and changes in the SF-36 domain "physical functioning" was performed using the Pearson method. A p-value $\leqslant 0.05$ was considered as significant.

\section{Results}

As shown in table 1, the patients experienced disabling shortness of breath, their timed walking distance was considerably reduced and baseline pulmonary function documented severe airflow obstruction as well as pulmonary hyperinflation. The mean oxygen tension in arterial blood was $65 \pm 1 \mathrm{mmHg}$, 
whereas the mean carbon dioxide tension in arterial blood was normal with $39 \pm 1 \mathrm{mmHg}$. The diffusing capacity for carbon monoxide was decreased to $42 \pm 2 \%$ predicted.

\section{Health-related quality of life}

At baseline HRQL was profoundly impaired. The lowest SF-36 scores were observed for Physical Functioning (16 \pm 2$)$ and Role-Physical (15 \pm 5$)$. Vitality $(32 \pm 3)$, General Health $(45 \pm 4)$, and Social Functioning $(51 \pm 5)$ showed marked deficits as well, whereas the impairments were less pronounced with respect to Role Emotional $(60 \pm 7)$ and Mental Health $(66 \pm 4)$ (table 1). Most patients did not suffer from relevant

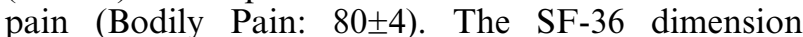
Physical Functioning was moderately correlated with the preoperative degree of dyspnoea $(\mathrm{r}=0.34, \mathrm{p}<0.05)$, and with the preoperative 6MWD $(r=0.48, p<0.005)$. No significant correlations were found between Physical Functioning and forced expiratory volume in one second (FEV1) \% pred, or the degree of hyperinflation, as assessed by the RV/TLC ratio, respectively.

The main finding was an improvement in scores of five domains of the SF-36 quality of life instrument (table 1, fig. 1). Marked increases were observed in the two dimensions Physical Functioning (16 $\pm 2-55 \pm 4$ ) and Role-Physical (15 $\pm 56-46 \pm 7)$. Relevant increases were also observed in Vitality $(32 \pm 3-60 \pm 3)$ as well as in Social Functioning (51 $\pm 5-82 \pm 3)$. The dimension, General Health also increased $(45 \pm 3-63 \pm 3 ; p<0.05)$. Mental Health, which was slightly reduced, improved to some extent, Role-Emotional tended to improve, whereas Bodily Pain remained unchanged. There were no differences between the responses of males and females. There was no correlation between the

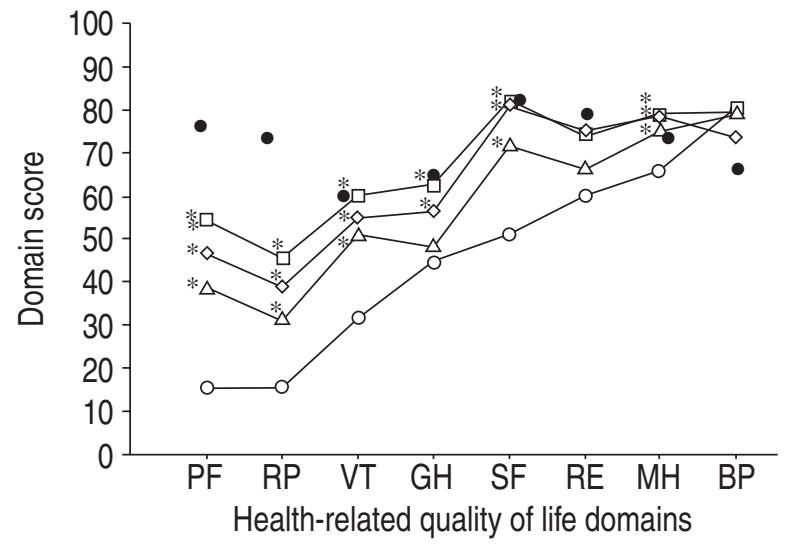

Fig. 1.-Change and time course of health-related quality of life domains (Short Form 36-item questionnaire) after lung volume reduction surgery for up to 2 yrs. PF: Physical Functioning (76); RP: Role-Physical (74); VT: Vitality (60); GH: General Health (64); SF: Social Functioning (81); RE: Role-Emotional (80); MH: Mental Health (75); BP: Bodily Pain (67) (numbers in brackets: scores for a healthy, sex-matched population of the same age). ๑: healthy populations; $\bigcirc$ : preoperative; $\square$ : 3 months; $\diamond$ : 12 months; $\triangle$ : 24 months. *: $\mathrm{p}<0.05$, compared to baseline. duration of hospital stay or perioperative morbidity with the subsequent health status in the patients.

The time course for the various HRLQ dimensions are shown in table 1 and figure 1 . Beneficial effects for Physical Functioning, Role Physical, Vitality, Social Functioning as well as for Mental Health were sustained for up to 2 yrs.

\section{Effects of lung volume reduction surgery on lung function and exercise performance}

Bilateral thoracoscopic LVRS resulted in significant and clinically relevant improvement of dyspnoea, pulmonary function, and 6MWD (table 1). Shortness of breath was considerably improved after surgery for up to 2 yrs and the mean 6MWD was higher by $68 \mathrm{~m}$ as compared to baseline at the end of the study period. The largest improvements in airflow obstruction and pulmonary hyperinflation were observed after 3 months. Thereafter, pulmonary function steadily declined, but remained significantly improved with respect to obstruction to airflow and reduction of hyperinflation for up to 2 yrs.

\section{Correlations between changes in lung function and physical functioning}

The SF-36 domain physical functioning assesses the individual's physical function, i.e. the limitation of a person in performing daily physical activities such as bathing or dressing. Since this domain discovered the largest improvement after LVRS, the correlations between changes in pulmonary function and changes in this parameter before and after surgery were investigated. Fair-to-moderate correlations between improvement in lung function and good correlations between changes in timed walking distance, decrease in shortness of breath and improvement in physical functioning were found (table 2, fig. 2)

\section{Discussion}

This prospective study in patients suffering from severe pulmonary emphysema showed that LVRS causes major improvements in quality of life lasting for at least 2 yrs, together with relief of dyspnoea, improvement in walking distance and lung function.

The effects of LVRS on pulmonary function were comparable to those reported in the literature $[9$, 28-31]. Recent randomized studies have shown that the degree of improved exercise tolerance in patients with far advanced emphysema achieved by LVRS exceeds that after pulmonary rehabilitation [32, 33]. The physiological mechanisms that account for the improvement in lung mechanics, exercise tolerance, and dyspnoea are multifactorial and include increase in lung elastic recoil and expiratory flow [34], decrease in hyperinflation [35], amelioration of respiratory muscle strength $[36,37]$ and a trend to normalization in breathing pattern [38].

Patients with advanced emphysema primarily suffer 
Table 2. - Correlations between Changes in Pulmonary Function and health-related quality of life Dimension

\begin{tabular}{|c|c|c|c|c|c|c|c|}
\hline \multirow{2}{*}{$\begin{array}{l}\text { Changes in HRQL } \\
\text { dimensions }\end{array}$} & \multirow{2}{*}{$\begin{array}{l}\text { Changes in lung } \\
\text { function }\end{array}$} & \multicolumn{2}{|c|}{3 months } & \multicolumn{2}{|c|}{12 months } & \multicolumn{2}{|c|}{24 months } \\
\hline & & $\mathrm{r}$ & p-value & $\mathrm{r}$ & $\mathrm{p}$-value & $\mathrm{r}$ & p-value \\
\hline Physical & $\Delta \mathrm{FEV}_{1} \%$ pred. & 0.39 & $<0.05$ & 0.49 & $<0.01$ & 0.57 & $<0.001$ \\
\hline \multirow[t]{3}{*}{ Functioning } & $\Delta \mathrm{RV} / \mathrm{TLC}$ & 0.35 & $<0.05$ & 0.57 & $<0.001$ & 0.55 & $<0.001$ \\
\hline & $\Delta 6 \mathrm{MWD} \mathrm{m}$ & 0.56 & $<0.001$ & 0.49 & $<0.01$ & 0.69 & $<0.001$ \\
\hline & $\Delta$ dyspnoea (MRC) & 0.66 & $<0.001$ & 0.59 & $<0.001$ & 0.66 & $<0.001$ \\
\hline \multirow[t]{4}{*}{ Vitality } & $\Delta$ FEV $1 \%$ pred. & 0.21 & NS & 0.18 & NS & 0.38 & $<0.05$ \\
\hline & $\Delta \mathrm{RV} / \mathrm{TLC}$ & 0.15 & NS & 0.34 & NS & 0.37 & $<0.05$ \\
\hline & $\Delta 6 \mathrm{MWD} \mathrm{m}$ & 0.31 & NS & 0.33 & NS & 0.47 & $<0.01$ \\
\hline & $\Delta$ dyspnoea (MRC) & 0.45 & $<0.01$ & 0.28 & NS & 0.44 & $<0.01$ \\
\hline Social & $\Delta$ FEV $_{1} \%$ pred. & 0.18 & NS & 0.35 & $<0.05$ & 0.41 & $<0.05$ \\
\hline \multirow[t]{3}{*}{ Functioning } & $\Delta \mathrm{RV} / \mathrm{TLC}$ & 0.17 & NS & 0.46 & $<0.01$ & 0.38 & $<0.05$ \\
\hline & $\Delta 6 \mathrm{MWD} \mathrm{m}$ & 0.44 & $<0.01$ & 0.41 & $<0.05$ & 0.57 & $<0.01$ \\
\hline & $\Delta$ dyspnoea (MRC) & 0.39 & $<0.05$ & 0.37 & $<0.05$ & 0.23 & NS \\
\hline
\end{tabular}

FEV1: forced expiratory volume in 1 second; RV: residual volume; TLC: total lung capacity; dyspnoea (MRC): Medical Research Council dyspnoea score; 6MWD: 6 min walking distance.

from shortness of breath, even during low levels of exercise. This reduces the patient's daily physical activity and has a considerable impact on wellbeing. Therefore, the primary treatment objectives for patients with emphysema are to reduce the degree of dyspnoea occurring at a distinct level of exercise, thereby improving HRQL. While several studies, including those of the present authors, have demonstrated significant improvements of dyspnoea and pulmonary function after LVRS, the purpose of the current investigation was to assess the effects of LVRS on HRQL as well, and to analyse the correlation between changes in functional parameters and alterations in aspects of quality of life.

The SF-36 questionnaire, which consists of 36 questions that cover eight quality of life domains, was selected for assessment of HRQL since it has been widely used and validated in patients with COPD [1] and applied for evaluation of the effect of LVRS [13, $14,16]$. In addition, the SF-36 is easy to administer and to analyse. Previous studies have shown variable relationships between lung function and scores for HRQL in patients with COPD, although dyspnoea seems to correlate best with several components of the SF-36 [1]. Furthermore, it has been shown that disease-specific instruments are not more sensitive for changes than the generic HRQL questionnaires [39].

To the best of the authors' knowledge, three groups have employed the SF-36 to assess the impact of LVRS on HRQL [13, 14, 16] . Preoperatively, pulmonary function of these patients was comparable to the cohort studied in this paper, i.e. all had a severe degree of airway obstruction (FEV $1<35 \%$ pred) and considerable pulmonary hyperinflation. The various SF-36 categories were reduced by a similar amount in those studies as was observed for the patients in the present study.

COOPER et al. [10] demonstrated significant increases in the SF-36 domains of Physical Functioning, Social Functioning, General Health and Vitality in a cohort of 20 patients, 3 months after bilateral LVRS; and YUSEN et al. [13], from the same group, confirmed these findings using a larger study population, 45 patients of whom 17 could be reassessed $1 \mathrm{yr}$ after surgery (table 3 ). These favourable results were corroborated by Moy et al. [14], who found a similar impact of LVRS on the various SF-36 scores 6 months after LVRS (table 3). In contrast to other
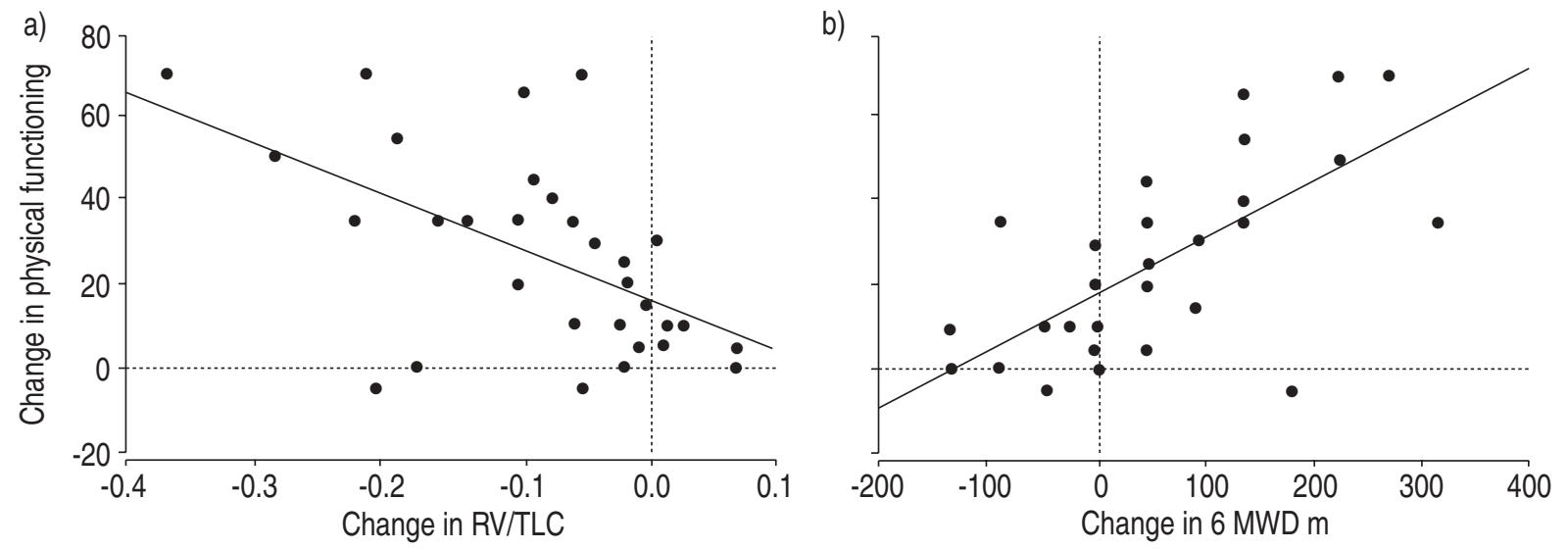

Fig. 2. - Relationship between the change in a) hyperinflation ( $r=-0.55, p=0.001)$ and b) 6-min walking distance (6MWD) ( $\mathrm{m}=0.69$, $\mathrm{p} \leqslant 0.001)$ and physical functioning 2 yrs after lung volume reduction surgery. RV: residual volume; TLC: total lung capacity. 
Table 3.-Comparison of Short Forms 36-item questionnaire scores and pulmonary function in present study with previously published values before and after lung volume reduction surgery

\begin{tabular}{|c|c|c|c|c|c|c|}
\hline & \multicolumn{2}{|c|}{ Current study } & \multicolumn{2}{|c|}{ YUSEN et al. [11] } & \multicolumn{2}{|c|}{ MoY et al. [13] } \\
\hline & Baseline & 6 months & Baseline & 6 months & Baseline & 6 months \\
\hline Subjects $n$ & 39 & 39 & 45 & 45 & 19 & 19 \\
\hline $\mathrm{PF}$ & $15.8 \pm 1.8$ & $51.1 \pm 3.9 *$ & $12 \pm 1.8$ & $59 \pm 3.6^{*}$ & $21.9 \pm 5.0$ & $40.0 \pm 6.7 *$ \\
\hline RP & $15.4 \pm 5.0$ & $53.4 \pm 6.9 *$ & $18 \pm 4.5$ & $75 \pm 4.9 *$ & $18.4 \pm 7.8$ & $53.9 \pm 9.8^{*}$ \\
\hline BP & $80.5 \pm 4.3$ & $79.7 \pm 4.5$ & $68 \pm 4.0$ & $79 \pm 3.7 *$ & $61.0 \pm 5.1$ & $73.7 \pm 5.0$ \\
\hline $\mathrm{GH}$ & $44.9 \pm 3.1$ & $60.7 \pm 3.8 *$ & $26 \pm 2.8$ & $56 \pm 3.7 *$ & $32.6 \pm 5.0$ & $48.0 \pm 6.5$ \\
\hline VT & $32.0 \pm 2.9$ & $60.4 \pm 3.3^{*}$ & $30 \pm 3.1$ & $70 \pm 2.8^{*}$ & $32.9 \pm 5.5$ & $55.0 \pm 5.8^{*}$ \\
\hline $\mathrm{SF}$ & $51.3 \pm 4.9$ & $85.5 \pm 3.4 *$ & $41 \pm 4.0$ & $85 \pm 3.4 *$ & $53.2 \pm 7.0$ & $75.8 \pm 7.6^{*}$ \\
\hline RE & $60.4 \pm 7.1$ & $79.3 \pm 5.8$ & $54 \pm 6.7$ & $85 \pm 4.6^{*}$ & $63.2 \pm 9.5$ & $84.2 \pm 7.8$ \\
\hline MH & $66.1 \pm 3.7$ & $79.0 \pm 2.6^{*}$ & $59 \pm 3.1$ & $80 \pm 3.1 *$ & $65.5 \pm 5.1$ & $76.6 \pm 4.2$ \\
\hline FEV1 $\%$ pred & $27.3 \pm 1.0$ & $42.9 \pm 2.4^{*}$ & $24 \pm 1.2$ & $39 \pm 2.4^{*}$ & $24 \pm 2.1$ & $32.0 \pm 2.5^{*}$ \\
\hline RV/TLC & $0.65 \pm 0.01$ & $0.51 \pm 0.02 *$ & $0.71^{\#}$ & $0.57^{\#}$ & & \\
\hline
\end{tabular}

Data are presented as mean \pm SEM unless otherwise stated. PF: Physical Functioning; RF: Role-Physical; BP: Bodily Pain; GH: General Health; VT: Vitality; SF: Social Functioning; RE: Role-Emotional; MH: Mental Health; FEV1: forced expiratory volume in 1 second; RV: residual volume; TLC: total lung capacity. ${ }^{\#}$ : values calculated from mean TLC and RV; *: $\mathrm{p}<0.05$ versus baseline.

groups who evaluated HRQL using alternative instruments [32], neither YUSEN et al. [13] nor MoY et al. [14] found significant changes in any of the SF-36 domains after pulmonary rehabilitation alone, which they mandatorily requested before accepting patients for surgery. In a group of 37 patients (functionally somewhat less impaired then those of YUSEN et al. [13] and Moy et al. [14]) smaller improvements than after LVRS were found in five of the eight quality-of-life subscales of the SF-36 after a 3-week comprehensive pulmonary rehabilitation [40].

The present results corroborate and extend these short-term observations of previous studies by demonstrating significant improvements in several domains of HRQL for at least 2 yrs after LVRS. In accordance with the concept of COPD affecting HRQL predominantly by dyspnoea and impaired physical performance, the domains of Physical Functioning and Role-Physical were those with the most prominent reductions before LVRS and with the most dramatic improvements by surgery. Nevertheless, General Health, Vitality and Social Functioning were also significantly improved. In contrast to other groups $[13,14,16]$, the patients in this study did not undergo systematic preoperative pulmonary rehabilitation. Since the degree of improvement in HRQL was comparable to others (table 3) who underwent LVRS after preoperative pulmonary rehabilitation $[13,14$, 16], the authors conclude that surgery is the essential component for the achievements of these favourable results.

It was observed, that even without a standardized rehabilitation during this follow-up, important SF-36 domains such as Physical Functioning, Vitality and Social Functioning remained considerably improved for up to 2 yrs. However, it is conceivable that these results could have been further improved by involving the patients in an ongoing rehabilitation programme. It has to be emphasized that pulmonary rehabilitation should not be replaced by LVRS; however, LVRS should be considered in order to treat a minority of patients who remain severely symptomatic despite best medical treatment and fulfilling the empirically elaborated criteria for a successful functional outcome after surgery [10, 41].

HRQL after LVRS has also been assessed by other instruments, such as the Nottingham Health Profile [10, 13], the Sickness Impact Profile [12, 18, 32, 42], the Chronic Respiratory Disease Questionnaire [15] and the St. George's respiratory Questionnaire [17]. In general, positive effects were found. However, these data are not directly comparable to the results found in the present study and other studies using the SF-36. Nevertheless, these investigations confirm that LVRS not only improves dyspnoea, pulmonary function and exercise tolerance, but has a favourable impact on various $H R Q L$ dimensions.

The authors acknowledge that incomplete followup may have biased the present findings, since patients who were satisfied with the results of LVRS are more likely to return for follow-up examinations. However, comparison of preoperative and 3 months postoperative data among patients available for the current analysis and those lost for follow-up does not reveal relevant differences with regard to pulmonary function and dyspnoea. This suggests that the potential bias is less than suspected.

Until now, no long-term data on the natural history of HRQL in COPD patients, who suffer from a disease severity comparable with those undergoing LVRS have been available. Some limited information can be derived from the publication of GEDDES et al. [33]. These authors found significant improvements in a SF-36 summary score at 6 and 12 months in the LVRS group as compared to the rehabilitation group, where quality of life tended to deteriorate over time. However, these authors used a HRQL summary score, the calculation of which is not described in the method section of their publication. In a few years, information regarding the natural history of HRQL in COPD patients under best medical care will be available from the National Emphysema Treatment 
Trial study, where patients are randomly assigned to conservative treatment or LVRS [43]. From all the available evidence, the natural history of the health status decline is most likely to be less pronounced after LVRS, as it is in a comparably severe emphysema population.

In conclusion, the present authors were able to demonstrate a major long-term benefit from lung volume reduction surgery on health-related quality of life in patients with advanced emphysema exceeding the improvement expected from any nonsurgical therapy.

\section{Appendix: the eight health components captured by the Short Form-36}

1) Physical Functioning: assesses the individual's physical function. Low scores mean that the individual is limited severely in performing all physical activities including bathing or dressing, due to health.

2) Role-Physical: assesses the potential of physical activity. Low scores mean that the individual has problems with work or other daily activities as a result of physical health.

3) Bodily Pain: assesses physical wellbeing and its consequences on physical activity. Low scores mean that bodily pain is very severe and extremely limiting.

4) General Health: evaluates the personal evaluation of physical and mental health. A low score not only means that the individual evaluates their personal health as poor, but also believes that it is likely to get worse.

5) Vitality: assesses physical and mental wellbeing. Whereas a high score means that the individual feels full of pep and energy all of the time, a low score means that the individual feels tired and worn out all of the time.

6) Social Functioning: assesses the limitation of social participation due to physical and mental disability. Low scores mean an extreme and frequent interference with normal social activities due to physical or emotional problems, whereas high scores mean that the individual performs normal social activities without interference due to physical or emotional problems.

7) Role-Emotional: assesses mental disability. A low score means that the individual has problems with work or other daily activities as a result of emotional problems.

8) Mental Health: assesses mental function and wellbeing. A low score means that an individual feels nervous and depressed all of the time.

\section{References}

1. Mahler DA, Mackowiak JI. Evaluation of the shortform 36-item questionnaire to measure health-related quality of life in patients with COPD. Chest 1995; 107: 1585-1589.

2. Casaburi R, Patessio A, Ioli F, Zanaboni S, Donner $\mathrm{CF}$, Wasserman K. Reduction in exercise lactic acidosis and ventilation as a result of exercise training in patients with obstructive lung disease. Am Rev Respir Dis 1991; 143: 9-18.

3. Buchi S, Villiger B, Sensky T, Schwarz F, Wolf C, Buddeberg C. Psychosocial predictors of long-term success of in-patient pulmonary rehabilitation of patients with COPD. Eur Respir J 1997; 10: 1272-1277.

4. Haggerty MC, Stockdale-Woolley R, ZuWallack R. Functional status in pulmonary rehabilitation participants. J Cardiopulm Rehabil 1998; 19: 35-42.

5. Lacasse Y, Wong E, Guyatt GH, King D, Cook DJ, Goldstein RS. Meta-analysis of respiratory rehabilitation in chronic obstructive pulmonary disease. Lancet 1996; 348: 1115-1119.

6. Singh SJ, Smith DL, Hyland ME, Morgan MD. A short outpatient pulmonary rehabilitation programme: immediate and longer-term effects on exercise performance and quality of life. Respir Med 1998; 92: 1146-1154.

7. White RJ, Rudkin ST, Ashley J, et al. Outpatient pulmonary rehabilitation in severe chronic obstructive pulmonary disease. $J$ R Coll Physicians Lond 1997; 31 : 541-545.

8. Young P, Dewse M, Fergusson W, Kolbe J. Improvements in outcomes for chronic obstructive pulmonary disease (COPD) attributable to a hospital-based respiratory rehabilitation programme. Aust NZ J Med 1999; 29: 59-65.

9. Bingisser R, Zollinger A, Hauser M, Bloch KE, Russi $\mathrm{EW}$, Weder W. Bilateral volume reduction surgery for diffuse pulmonary emphysema by video-assisted thoracoscopy. J Thorac Cardiovasc Surg 1996; 112: 875-882.

10. Cooper JD, Trulock EP, Triantafillou AN, et al. Bilateral pneumectomy (volume reduction) for chronic obstructive pulmonary disease. J Thorac Cardiovasc Surg 1995; 109: 106-119.

11. McKenna RJ Jr, Brenner M, Gelb AF, et al. A randomized, prospective trial of stapled lung reduction versus laser bullectomy for diffuse emphysema. J Thorac Cardiovasc Surg 1996; 111: 317-322.

12. Cordova F, O'Brien G, Furukawa S, Kuzma AM, Travaline J, Criner GJ. Stability of improvements in exercise performance and quality of life following bilateral lung volume reduction surgery in severe COPD. Chest 1997; 112: 907-915.

13. Yusen RD, Trulock EP, Pohl MS, Biggar DG, The Washington University Emphysema Surgery Group. Results of lung volume reduction surgery in patients with emphysema. Semin Thorac Cardiovasc Surg 1996; 8: 99-109.

14. Moy ML, Ingenito EP, Mentzer SJ, Evans RB, Reilly JJJ. Health-related quality of life improves following pulmonary rehabilitation and lung volume reduction surgery. Chest 1999; 115: 383-389.

15. Bagley PH, Davis SM, O'Shea M, Coleman AM. Lung volume reduction surgery at a community hospital: program development and outcomes. Chest 1997; 111: 1552-1559.

16. Ferguson GT, Fernandez E, Zamora MR, Pomerantz M, Buchholz J, Make BJ. Improved exercise performance following lung volume reduction surgery for emphysema. Am J Respir Crit Care Med 1998; 157: 1195-1203.

17. Norman M, Hillerdal G, Orre L, et al. Improved lung function and quality of life following increased elastic recoil after lung volume reduction surgery in emphysema. Respir Med 1998; 92: 653-658. 
18. O'Brien GM, Furukawa S, Kuzma AM, Cordova F, Criner GJ. Improvements in lung function, exercise, and quality of life in hypercapnic COPD patients after lung volume reduction surgery. Chest 1999; 115: $75-84$.

19. Anderson KL. Change in quality of life after lung volume reduction surgery. Am J Crit Care 1999; 8: 389-396.

20. Cooper JD, Patterson GA. Lung volume reduction surgery for severe emphysema. Semin Thorac Cardiovasc Surg 1996; 8: 52-60.

21. Russi EW, Stammberger U, Weder W. Lung volume reduction surgery for emphysema. Eur Respir J 1997; 10: $208-218$.

22. American Thoracic Society. Surveillance for respiratory hazards in the occupational setting. Am Rev Respir Dis 1982; 126: 952-956.

23. American Thoracic Society. Standardization of spirometry: 1987 update. Am Rev Respir Dis 1987; 13: 285-298.

24. Quanjer PH, Tammeling GJ, Pederson OF, Peslin R, Yernault JC. Report working party standardization of lung function tests European Community for Steel and Coal. Official statement of the European Respiratory Society. Lung volumes and forced ventilatory flows. Eur Respir J 1993; 6: Suppl. 16, 5-40.

25. Cotes JE, Chinn DJ, Quanjer PH, Roca J, Yernault JC. Report working party standardization of lung function tests European Community for Steel and Coal. Official statement of the European Respiratory Society. Standardization of the measurement of transfer factor (diffusing capacity). Eur Respir $J$ 1993; 6: Suppl. 16, 41-52.

26. Bullinger M. German translation and psychometric testing of the SF-36 Health Survey: preliminary results from the IQOLA Project. International Quality of Life Assessment. Soc Sci Med 1995; 41: 1359-1366.

27. Stammberger U, Thurnheer R, Bloch KE, et al. Thoracoscopic bilateral lung volume reduction for diffuse pulmonary emphysema. Eur J Cardiothorac Surg 1997; 11: 1005-1010.

28. Cooper JD, Patterson GA, Sundaresan RS, et al. Results of 150 consecutive bilateral lung volume reduction procedures in patients with severe emphysema. J Thorac Cardiovasc Surg 1996; 112: 13191330.

29. Gelb A, McKenna RJ, Brenner M, et al. Lung function 54 months post lung volume reduction surgery. Am J Respir Crit Care Med 2000; 161: 585.

30. Teschler H, Thompson AB, Stamatis G. Short- and long-term functional results after lung volume reduction surgery for severe emphysema. Eur Respir J 1999; 13: $1170-1176$

31. Wisser W, Tschernko E, Senbaklavaci O, Kontrus M, Wanke T, Klepetko W. Functional improvements after volume reduction: sternotomy versus videoendoscopic approach. Ann Thorac Surg 1997; 63: 822-828.

32. Criner GJ, Cordova FC, Furukawa S, et al. Prospective randomized trial comparing bilateral lung volume reduction surgery to pulmonary rehabilitation in severe chronic obstructive pulmonary disease. $\mathrm{Am}$ J Respir Crit Care Med 1999; 160: 2018-2027.

33. Geddes D, Davies M, Koyama H, et al. Effect of lung-volume-reduction surgery in patients with severe emphysema. $N$ Engl J Med 2000; 343: 239-245.

34. Sciurba FC, Rogers RM, Keenan RJ, et al. Improvement in pulmonary function and elastic recoil after lung-reduction surgery for diffuse emphysema. $N \mathrm{Engl}$ J Med 1996; 334: 1095-1099.

35. Brantigan OC, Kress MB, Mueller EA. The surgical approach to pulmonary emphysema. Dis Chest 1961; 39: 485-501.

36. Criner G, Cordova FC, Leyenson V, et al. Effect of lung volume reduction surgery on diaphragm strength. Am J Respir Crit Care Med 1998; 157: 1578-1585.

37. Teschler H, Stamatis G, El-Raouf Farhat AA, Meyer FJ, Costabel U, Konietzko N. Effect of surgical lung volume reduction on respiratory muscle function in pulmonary emphysema. Eur Respir J 1996; 9: 17791784.

38. Bloch KE, Li Y, Zhang J, Bingisser R, Kaplan V, Russi EW. Effect of surgical lung volume reduction on breathing patterns in severe pulmonary emphysema. Am J Respit Crit Care Med 1997; 156: 553-560.

39. Harper R, Brazier JE, Waterhouse JC, Walters SJ, Jones NM, Howard P. Comparison of outcome measures for patients with chronic obstructive pulmonary disease (COPD) in an outpatient setting. Thorax 1997; 52: 879-887.

40. Boueri FM, Bucher-Bartelson BL, Glenn KA, Make BJ. Quality of life measured with a generic instrument (Short Form-36) improves following pulmonary rehabilitation in patients with COPD. Chest 2001; 119: 77-84.

41. Thurnheer R, Engel H, Weder W, et al. Role of lung perfusion scintigraphy in relation to chest CT and pulmonary function in the evaluation of candidates for lung volume reduction surgery. Am J Respir Crit Care Med 1999; 159: 301-310.

42. Leyenson V, Furukawa S, Kuzma AM, Cordova F, Travaline J, Criner GJ. Correlation of changes in quality of life after lung volume reduction surgery with changes in lung function, exercise, and gas exchange. Chest 2000; 118: 728-735.

43. Rationale and design of the National Emphysema Treatment Trial (NETT): a prospective randomized trial of lung volume reduction surgery. $J$ Thorac Cardiovasc Surg 2001; 158: 518-528.

44. Ware JE Jr, Snow KK, Kosinski M, Gandek B. SF-36 Health Survey. Manual and Interpretation Guide. Boston, MA, Nimrod Press, 1993. 